\title{
Deficiência múltipla, sistemas de apoio e processos de escolarização ${ }^{1}$
}

\author{
Maira Gomes de Souza da Rocha* \\ Márcia Denise Pletsch**
}

\begin{abstract}
Resumo
Este artigo problematiza as condições de escolarização de alunos com deficiência múltipla severa. A pesquisa qualitativa foi realizada em escolas de dois municípios da Baixada Fluminense/RJ, por meio de entrevistas com professores de turmas comuns de ensino, classes especiais, do Atendimento Educacional Especializado (AEE), e gestores da área de educação especial. Os resultados analisados à luz da perspectiva histórico-cultural mostraram a fragilidade das práticas educativas e do sistema de apoios especializados para atender às especificidades de aprendizagem destes sujeitos. Igualmente, mostraram falta de conhecimento dos profissionais da educação sobre as implicações da deficiência múltipla para a sua escolarização. Por último, o artigo discute possibilidades para que tais sujeitos participem das práticas educativas.

Palavras-chave: deficiência múltipla, processos de escolarização, sistemas de apoio.
\end{abstract}

\section{Discapacidad múltiple, sistemas de apoyo y procesos de escolarización}

\section{Resumen}

Este artículo problematiza las condiciones de escolarización de alumnos con discapacidad múltiple severa. La investigación cualitativa fue realizada en escuelas de dos municipios de la Baixada Fluminense/RJ, por medio de entrevistas con profesores de clases comunes de enseñanza, clases especiales, de la Atención Educativa Especializada (AEE), y gestores del área de educación especial. Los resultados analizados a la luz de la perspectiva histórico-cultural mostraron la fragilidad de las prácticas educativas y del sistema de apoyos especializados para atender a las especificidades de aprendizaje de estos sujetos. Asimismo, mostraron la falta de conocimiento de los profesionales de la educación sobre las implicaciones de la discapacidad múltiple para su escolarización. Por último, el artículo discute posibilidades para que tales sujetos participen en las prácticas educativas.

Palabras clave: discapacidad múltiple, procesos de escolarización, sistemas de apoyos.

\section{Multiple disabilities, support systems and schooling processes}

\begin{abstract}
This article problematizes the conditions of schooling of students with severe multiple deficiencies. The qualitative research was carried out in schools of two counties of Baixada Fluminense/RJ, through interviews with teachers of common teaching classes, special classes, Specialized Educational Assistance (SEA) and special education managers. The results analyzed in the light of the historical-cultural perspective showed the fragility of educational practices and specialized educational supports to meet the learning specificities of these subjects. They also showed the lack of clarity understanding of education professionals about the implications of multiple disabilities for their schooling. Finally, it discusses possibilities for such subjects to participate in educational practices.
\end{abstract}

Keywords: multiple disabilities, schooling processes, support systems.

\section{Introdução}

Um desenvolvimento não é garantido pelas aprendizagens, pois, com efeito, o processo escolar tem seus encadeamentos, sua lógica e sua organização complexa que lhes são próprias. Os ensinamentos se desenvolvem em função de um planejamento determinado anteriormente, de uma maneira sequencial, na forma de lições, de deveres, que são organizados segundo os diferentes campos e materiais a ensinar. É essa organização que
Vigotski tem em vista quando ele caracteriza as leis da aprendizagem. (FRIEDRICH, 2012, p. 111)

A deficiência múltipla tem provocado inúmeras discussões sobre a sua definição e a população que pode ser caracterizada como tal. Não há consenso na literatura nacional e internacional sobre este aspecto. As discordâncias em relação à conceituação de deficiência múltipla muito se devem ao fato de alguns a conceberem como uma

*Endereço Eletrônico: mairagsrocha@gmail.com

**Endereço Eletrônico: marciadenisepletsch@gmail.com 
deficiência inicial que foi geradora de outras, enquanto que outros a consideram como uma associação entre duas ou mais deficiências, sem necessariamente uma ter sido causa do desenvolvimento da outra (ROCHA; PLETSCH, 2015). Outro ponto de discussão diz respeito a necessidade de haver ou não a ocorrência da deficiência intelectual para que o caso em questão seja considerado deficiência múltipla (TEIXEIRA; NAGLIATE, 2009; ROCHA; PLETSCH, 2015; ROCHA, 2014; 2018). Para fins deste artigo a entendemos como um conjunto de duas ou mais deficiências - de ordem física, sensorial, mental, entre outras - associadas que afetam em maior ou menor intensidade o funcionamento individual $\mathrm{e}$ social dos sujeitos.

A esse respeito, destacamos que no contexto dos estudos realizados pelo grupo de pesquisa Observatório de Educação Especial e Inclusão Educacional (ObEE/UFRRJ) ${ }^{2}$, os educandos com deficiência múltipla apresentavam necessariamente alguma associação de deficiências envolvendo a deficiência intelectual (PLETSCH; ROCHA; OLIVEIRA, 2016). Contudo, é importante dizer que pesquisadores (NUNES, 2001; BERNARDO, 2010) e instituições internacionais nem sempre reconheçam esta possibilidade.

A deficiência múltipla manifesta-se de variadas formas e expressa condições diversas de atuação da pessoa no meio ambiente. Essas diferenças às vezes decorrem de complexos fatores que, interagindo, influenciam no intercâmbio com o mundo físico e a vida social. A funcionalidade das pessoas com múltipla deficiência depende de aspectos individuais, como as limitações impostas pelas deficiências, mas, sobretudo, das oportunidades oferecidas a estes sujeitos (BRASIL, 2000). Tendo em vista a abrangência da deficiência múltipla, determinados autores delimitam um grupo o qual nomeiam de deficiência múltipla sensorial (MAIA; GIACOMINI; ARÁOZ, 2009; SOUZA M., 2010; MAIA; GIACOMINI, 2010; ARÁOZ; COSTA, 2015; MOREIRA, 2017; 2018). Deste modo, uma pessoa com deficiência múltipla sensorial é aquela que apresenta deficiência auditiva ou visual associadas a outras condições de comportamento e comprometimentos, sejam eles na área física, intelectual ou emocional (SOUZA M., 2010). Também é oportuno mencionar a respeito da surdocegueira, que não é um caso de deficiência múltipla nem mesmo de deficiência múltipla sensorial. Isso ocorre porque a surdocegueira é uma deficiência estritamente sensorial, envolvendo apenas as deficiências auditiva e visual.

Apesar do crescimento das matrículas desta população em escolas públicas de Educação Básica, ainda enfrentamos no país um conjunto de desafios para garantir a escolarização desse alunado. Rocha (2018) apresenta dados do Censo Escolar que registrou, no contexto nacional, crescimento nas matrículas de estudantes com deficiência múltipla na Educação Básica em sua totalidade, passando de $62.283 \mathrm{em} 2003$ para $70.471 \mathrm{em} \mathrm{2015}$, representando crescimento de $13 \%$. Especificamente, nas classes comuns do ensino regular, os dados mostram crescimento de $449 \%$, passando de 7.640 estudantes em 2003 para 41.948 em $2015^{3}$.

Entendemos que esse crescimento tem relação com a disseminação da Política Nacional de Educação Especial na Perspectiva da Educação Inclusiva (BRASIL, 2008). Aliás, é importante sinalizar que a referida política não menciona diretamente a deficiência múltipla (ARAÓZ, 2010). Para Rocha (2014), "a não explicitação direta a respeito da deficiência múltipla nos documentos oficiais acaba por prejudicar o desenvolvimento de ações [...]. Desta forma, o suprimento das necessidades mais específicas deste público acaba por não ser priorizado" (p. 30). O mesmo ocorre no texto da Resolução n.4/2009, do Conselho Nacional de Educação, da Câmara de Educação Básica que institui as Diretrizes Operacionais para o AEE na Educação Básica (BRASIL, 2009). Destacamos a importância desse tipo de atendimento para pessoas com deficiências múltiplas. No entanto, a legislação não cita a deficiência múltipla, deixando-a apenas implícita no artigo 4 ao mencionar o seu público alvo.

Paralelamente, estudos vêm mostrando a falta de investigações envolvendo a temática, sobretudo, se considerarmos as questões educativas (PLETSCH, 2015; ROCHA; PLETSCH, 2015; NUNES, 2016; ROCHA, 2018). Pessoas com múltiplas deficiências em sua maioria apresentam quadros que exigem suportes especializados. $\mathrm{O}$ pouco conhecimento a respeito da deficiência múltipla e de suas manifestações dificulta a elaboração de ações pertinentes e a articulação entre diferentes setores de serviços na sociedade.

Nesse contexto, temos desenvolvido no ObEE um conjunto de pesquisas sobre a estrutura e o funcionamento das redes de ensino na Baixada Fluminense/ RJ no que diz respeito à escolarização do público da Educação Especial. No período de 2013 a $2014^{4}$, realizamos um projeto de pesquisa sobre a escolarização de alunos com múltiplas deficiências em uma escola - de município da 
referida região - sobre o desenvolvimento de quatro alunos com múltiplas deficiências, não oralizados com base na metodologia da pesquisa-ação. Também analisamos o trabalho pedagógico realizado para esses alunos no AEE oferecido na sala de recursos multifuncionais.

Os resultados evidenciaram, entre outros aspectos, o empenho das docentes em realizar um trabalho qualificado junto aos alunos, mas também, as inúmeras dificuldades decorrentes da falta de recursos de tecnologia assistiva e de comunicação alternativa. A pesquisa também mostrou que as escolas têm problemas de infraestrutura, materiais e recursos adequados para atender às necessidades educacionais especiais que são muito específicas para cada aluno com múltiplas deficiências; problemas relacionados ao transporte adaptado público e/ou escolar para que os alunos cheguem à escola; além da falta de articulação do sistema educacional com o sistema de saúde, uma vez que muitos alunos com essas deficiências sofrem com convulsões e apneias sem terem o acompanhamento clínico necessário.

No caso das práticas pedagógicas, a pesquisa mostrou que falta aos docentes conhecimentos específicos para efetivar atividades pedagógicas que promovam o desenvolvimento desses alunos. Rocha (2014) acrescentou a este conjunto de dados a necessidade de que docentes conheçam e se apropriem da comunicação alternativa $(\mathrm{CA})^{5}$ como aspecto fundamental para atuar com alunos com essa deficiência, em especial, quando não oralizados. Estratégias e recursos dessa área poderiam ser utilizados a fim de atender às necessidades educacionais de seus alunos, contribuir para os processos de ensino e aprendizagem e, consequentemente, para o seu desenvolvimento.

Tomando esses resultados como base, em $2015^{6}$, iniciamos um projeto objetivando acompanhar longitudinalmente a trajetória escolar dos mesmos quatro sujeitos com múltiplas deficiências que participaram da pesquisa anterior. Em outros termos, este artigo problematiza as condições de escolarização de alunos com deficiências múltiplas severas, apontando possibilidades e desafios a serem enfrentados para garantir uma escolarização que promova processos de ensino e aprendizagem considerando as demandas de acessibilidade desse alunado para que participem das práticas educacionais. Para tal, tomamos o conceito de compensação de Vigotski como referência para discutir as possibilidades de escolarização a partir do oferecimento de apoios e suportes demandados por estes sujeitos, de forma a favorecer a sua participação nos processos educacionais e sociais.

\section{Considerações metodológicas $^{7}$}

Os dados de pesquisa aqui apresentados referem-se a estudos realizados em dois momentos distintos. O primeiro, no período de 2013 a 2017, mediante o acompanhamento das trajetórias de quatro alunos com deficiência múltipla, matriculados a princípio, no ensino comum e no Atendimento Educacional Especializado (AEE), modalidade sala de recursos (Igor, Fernando, Marcelo e Eliza). Nesta fase, as informações de campo foram sistematizadas a partir do relato de duas professoras que haviam trabalhado com os alunos. Pesquisas que acompanhem por um longo período alunos com deficiência múltipla são importantes, pois permitem conhecer o seu processo educacional, as dificuldades enfrentadas e as possibilidades construídas pelas escolas e redes de ensino, assim como pelos próprios sujeitos.

Esses dados, num segundo momento, foram relacionados com resultados de uma pesquisa etnográfica que acompanhou três sujeitos com deficiência múltipla (Paulo, Flávia e Rodrigo), alunos de duas diferentes escolas de outro município, entre 2016 e 2017. Desses três alunos, dois estavam matriculados em classes especiais (uma em cada escola) e o terceiro aluno estava no ensino comum com o suporte do AEE (em mesma escola de uma das classes especiais). Para fins deste artigo, usaremos prioritariamente dados obtidos nesses dois estudos por meio de entrevistas semiestruturadas realizadas com gestores e as professoras das classes comuns, classes especiais e do AEE.

Assim como Orlando e Caiado (2014, p.818), não consideramos a trajetória individual dos sujeitos pesquisados "como algo lógico em um percurso linear; mas sim, que esse sujeito se enreda nas forças sociais não necessariamente coerentes, quando é levado a optar, por exemplo, pelos estudos". Isto é, as trajetórias dos sujeitos foram analisadas considerando as condições sociais em que viviam.

Ressaltamos que os dados aqui apresentados foram construídos ao logo de vários anos de pesquisa em diferentes escolas de duas redes públicas de educação, ou seja, de duas diferentes cidades, mas que estão localizadas numa mesma região, a Baixada Fluminense, no Estado do Rio de Janeiro. A Baixada Fluminense é conhecida pelos seus grandes 
problemas sociais, ambientais e educacionais.

\section{Caminhos e possibilidades de escolarização}

No período de 2013 a 2017, acompanhamos as trajetórias de Igor (13 anos), Fernando (16 anos), Marcelo (14 anos) e Eliza (22 anos). Os dados revelaram que, apesar dos avanços em termos legais, a política de educação inclusiva ainda não provocou mudanças na vida escolar destes sujeitos.

Marcelo (cadeirante, não oralizado) tem comprometimentos motores severos e deficiência intelectual e ainda enfrenta problemas sérios de saúde. Com isso, em 2015, saiu da escola especial e foi para uma escola comum da mesma rede municipal de ensino, mas em decorrência dos problemas de saúde e locomoção acabou faltando muitas aulas.

Igor é surdo e tem Síndrome de Down. Em 2016, foi encaminhado para uma classe especial, após anos matriculado no ensino comum e em sala de recursos, mas frequentando praticamente apenas a segunda. Na classe especial, assim como observado nos espaços anteriores, continuou sem usar a Língua Brasileira de Sinais (Libras). Esse aspecto prejudicou enormemente a sua escolarização. Segundo relato da professora da sala de recursos, a partir da sua chegada na escola, ele passou a ser menos agressivo. No entanto, em nossa análise, as suas especificidades demandariam intervenções mais sistematizadas em diferentes áreas, em particular, no que diz respeito ao ensino de Libras. Em 2017, aos 13 anos de idade, Igor abandonou a escola.

Eliza usa cadeira de rodas e apresenta deficiência intelectual. Em 2015, em função de ter completado a maior idade, foi transferida da escola em que estava matriculada no ensino comum com o suporte da sala de recursos para um centro integrado destinado para pessoas jovens e adultas com deficiência do próprio município. Em 2017 abandonou a instituição.

Fernando, que tem paralisia cerebral, é usuário de cadeira de rodas e não possui linguagem oral. Ele foi o único que deu continuidade aos estudos e estava, em 2017, matriculado no $5^{\circ}$ ano do Ensino Fundamental com o suporte do AEE, por meio da sala de recursos.

Como podemos depreender, as políticas educacionais não garantiram a inserção destes sujeitos em práticas e processos de ensino e aprendizagem efetivas. Além das situações de saída do ensino comum, ingressando em classes especiais ou instituições do tipo, observou-se que, por fim, o abandono da trajetória escolar foi algo recorrente. $\mathrm{Ou}$ seja, a deficiência múltipla continua marcando a trajetória escolar dos sujeitos, mas também, neste caso, as suas vidas. Nesse sentido, algumas questões se fazem necessárias: Como é identificada a deficiência múltipla no contexto escolar? Quais são as concepções docentes predominantes sobre $\mathrm{o}$ processo educacional desse alunado? Que estratégias poderiam ser usadas para garantir a participação desses alunos nas práticas educativas? Que suportes e apoios são indispensáveis?

Para compreender tais aspectos inicialmente é importante sinalizar que, à luz da perspectiva histórico-cultural de Vigotki (1997), o ambiente escolar é considerado potencializador para o desenvolvimento humano. Deste modo, diante dos desafios apontados para a concretização de processos efetivos de escolarização, tomamos como referência essa perspectiva pelas reflexões desenvolvidas sobre a aprendizagem, considerando as especificidades de desenvolvimento que os sujeitos podem apresentar.

Para Vigotski, a deficiência é ocasionada pela relação entre a lesão orgânica e a cultura (VIGOTSKI, 1997). Deste modo, o autor fortalece suas postulações e princípios sobre o desenvolvimento cultural, situando-o como um processo que "[...] corresponde ao desenvolvimento psíquico que se produz entrelaçado ao desenvolvimento histórico da sociedade" (SOUZA; DAINEZ, 2016, p. 61). A partir deste ponto, o teórico elaborou preceitos sobre o processo de compensação.

O conceito de compensação foi intensamente trabalhado por Vigotski $(1997,2011)$ nos estudos da defectologia. Suas postulações são inovadoras e despertam crescentemente $o$ interesse de pesquisadores pelo mundo (VAN DER VEER; VALSINER, 2009; dentre outros). Dainez e Smolka (2014) ressaltam que a compensação é o principal conceito trabalhado por Vigotski, quando aborda o desenvolvimento da pessoa com deficiência.

Vigotski compreende a compensação como uma reação da personalidade ante à deficiência no processo de desenvolvimento da criança "com defeito" (VIGOTSKI, 1997; PADILHA, 2000; LIMA, ARAÚJO; MORAES, 2010; DAINEZ, 2014). Segundo ele, o conflito que geralmente acontece por causa da deficiência e que comumente traz muitas dificuldades para a vida do sujeito também pode criar possibilidades e estímulos de compensação. Deste modo, a deficiência ou o defeito (como ele dizia) torna-se o ponto de partida e a principal força motriz por trás do desenvolvimento psíquico da personalidade (VIGOTSKI, 1997; 2011). É oportuno ressaltar que em momento algum 
Vigotski trabalha a ideia da compensação como cura da deficiência. Ele localiza o processo de compensação como propiciador do desenvolvimento de áreas potenciais.

Também é plausível destacar que a compensação pode ter diferentes desfechos, porém, qualquer que seja o seu resultado, o desenvolvimento complicado pela deficiência constitui sempre um processo criador de construção e reconstrução da personalidade (VIGOTSKI, 1997). Ainda a este respeito, o autor destaca que o desenvolvimento pode acontecer por caminhos indiretos. Eles podem ser trilhados por meio de veículos não convencionais, ou necessitar de recursos ou condições diferenciadas que venham a atender às particularidades implícitas no processo de desenvolvimento. Caso esses caminhos levem à constituição de processos de compensação, o ambiente social terá cumprido o seu papel de favorecer o desenvolvimento pelo viés cultural, ao invés de restringi-lo às condições fisiológicas, a princípio não favoráveis.

Neste ponto é que se evidencia a importância de uma escolarização que leve em conta as especificidades dos estudantes com múltiplas deficiências, considerando e correspondendo às suas necessidades educacionais especiais (KASSAR, 1999). É neste sentido que as análises sobre o processo de compensação contribuem para que processos de ensino e aprendizagem sejam beneficiados.

As pesquisas empíricas que realizamos nos mostraram que, para a efetivação de uma escolarização com o objetivo de propiciar desenvolvimento, é imprescindível que se garantam determinadas condições e suportes para que este processo de compensação seja desencadeado como mais adiante iremos discutir. No entanto, questões relacionadas à identificação dos alunos com múltiplas deficiências nas escolas e até mesmo concepções equivocadas dos profissionais que atuam com os mesmos sobre os seus potenciais de desenvolvimento ainda influenciam de forma negativa na organização, no planejamento e na condução das práticas pedagógicas dirigidas para estes alunos.

Em relação a este ponto, verificou-se que, em grande medida, as escolas apresentam dificuldades na identificação dos alunos com múltiplas deficiências. Nos dois estudos, verificamos no acompanhamento dos alunos, erros na interpretação dos laudos apresentados no ato da matrícula. Estes se somam a dúvidas em relação ao que de fato seja o conceito de deficiência múltipla, aspectos que contribuem para que esses alunos não sejam identificados ou ainda, em muitos casos, alunos que não a apresentam são identificados como tal. Esses aspectos também foram identificados nas entrevistas com todas as docentes participantes. A este respeito, uma observação mais precisa do aluno juntamente com o conhecimento do que seja a deficiência múltipla poderia contribuir, porém, nem sempre isso acontece no ambiente da escola por causa de suas inúmeras demandas. Somando-se a isso ainda há de se considerar a forte influência do modelo médico de compreensão da deficiência nas práticas avaliativas, em detrimento do modelo social e de direitos (GLAT; BLANCO, 2007; PLETSCH; PAIVA, 2018).

Também ficou evidente, no contato com as professoras e equipes diretivas, que ainda faltam conhecimentos não apenas sobre a deficiência múltipla, mas também sobre as peculiaridades de desenvolvimento destes alunos. Os relatos dos professores e demais profissionais que atuam nas escolas reforçam isso ao indicar a baixa expectativa em relação às potencialidades de desenvolvimento dos alunos com deficiência múltipla, bem como em relação aos sentidos e propósitos da escolarização para este público. Os trechos coligidos a seguir são ilustrativos dessas visões:

Após a reunião sobre a proposta de pesquisa, a diretora perguntou-me por que eu teria que fazer a pesquisa com os alunos com deficiência múltipla pois não achava que seria proveitoso realizar esse trabalho com eles pois dificilmente aprendem alguma coisa e talvez isso prejudicasse a minha pesquisa. Propôs que eu fizesse o estudo com outra turma, que tivesse rendimento melhor (Registro em Diário de Campo - Escola 2 25/04/17).

PROFESSORA AEE: Quais os objetivos, o que a gente espera, né? [pausa] Socialização. Acho que não tem muito além disso, eu sinceramente, é a minha opinião, né? (Transcrição de entrevista realizada com a professora de sala de recursos/AEE - Escola 2).

VICE-DIRETORA: Pois é... a gente tem que estar redescobrindo isso todo dia [sentidos da escolarização]. Porque é difícil até traçar objetivo para esses alunos. É muito difícil... a gente tem que ir e de repente, volta. Vai e volta. Eu, particularmente, trabalhando com uma aluna assim... Eu muitas vezes não sabia o que fazer. Assim... Tudo que eu fazia com ela era muito mecânico... me dava uma agonia porque eu não via sentido para ela. Ela fazia, dava aquelas rabiscadas e eu sinceramente... eu não via... Não via muito sentido (Transcrição de entrevista realizada com vice-diretora da Escola 2). 
Ao nosso ver, essas concepções e até mesmo a falta de conhecimento dos profissionais acabam impactando nas propostas de ensino que, em geral, subestimavam as potencialidades e não buscavam estratégias de intervenção que buscassem as possibilidades dos sujeitos. Os dados revelaram, por exemplo, que apesar da não oralidade dos alunos, não havia propostas envolvendo recursos de tecnologias assistivas e da comunicação alternativa, as quais tem se mostrado importantes recursos pedagógicos para os processos de ensino e aprendizagem de alunos com deficiência múltipla (ROCHA, 2014; MOREIRA, 2017; 2018). Também se evidenciou a falta de articulação e colaboração entre as docentes do AEE, da sala comum e do agente ${ }^{8}$ de apoio à inclusão. Segundo Marin e Braun (2013), planejar ações conjuntas entre os profissionais envolvidos com a educação de pessoas com deficiências é fundamental para ampliar as possibilidades de participação destes nos processos de ensino e aprendizagem.

Além disso, nossos estudos sinalizaram que o acesso à escolarização desses alunos é garantido por meio da matrícula, mas ela não se efetiva completamente. Essa firmação é possível, pois ficaram evidentes problemas de frequência e de participação nas aulas, justamente dessa parcela que mais precisaria de intervenções educativas. O quadro a seguir traz números a respeito da frequência de três sujeitos participantes da segunda pesquisa:

QUADRO 1 - Percentual de frequência à escola

\begin{tabular}{|c|c|c|c|c|}
\hline Alunos e idade & $\begin{array}{c}\text { Dia letivos previstos } \\
\text { para o período }\end{array}$ & Faltas & $\begin{array}{c}\text { Dias em que não } \\
\text { houve aula }\end{array}$ & $\begin{array}{c}\text { Percentual de } \\
\text { frequência }\end{array}$ \\
\hline Paulo (10 anos) & 30 & 6 & 6 & $60 \%$ \\
\hline Flávia (12 anos) & 27 & 13 & 9 & $18,5 \%$ \\
\hline Rodrigo (7 anos) & 30 & 10 & 12 & $26,6 \%$ \\
\hline
\end{tabular}

Fonte: Banco de dados do ObEE

Esses dados mostram que apesar das políticas de acesso, esses alunos não têm assumido o direito de estar na escola o que implica na não efetivação de um processo de escolarização como o expresso na legislação do nosso país (BRASIL, 1996; 2008; 2009). Considerando que o nosso principal foco de análise é a relação entre escolarização e desenvolvimento, consideramos que é primordial e urgente, primeiramente garantir que estes alunos frequentem o espaço escolar e que esta escolarização venha a se concretizar por meio de ações que oportunizem participação e construção de conhecimentos. Ainda de acordo com nosso estudo a falta de frequência está relacionada a diversas questões, mas uma delas chamou a nossa atenção. Segundo relato de uma das mães "não adianta levar para a escola se não aprende".

Propomos como uma das alternativas para garantir a participação plena destes sujeitos nos processos educacionais uma combinação flexível de apoios e suportes especializados para além daqueles já previstos, como o AEE e o agente de apoio a inclusão. Para tal, com base na classificação de sistemas de apoios indicados pela Associação Americana de Deficiência Intelectual e Desenvolvimento - AAIDD (2011) e a Classificação Internacional de Funcionalidade, Incapacidade e
Saúde - CIF (OMS, 2004), sugerimos alguns caminhos para a escolarização de sujeitos com deficiência múltipla severa.

Nossa proposta é justamente, por meio de um sistema de apoio, proporcionar possibilidades de desenvolvimento para que ocorram as compensações em termos vigotskianos. Certamente, muito ainda temos para pesquisar, mas compreendemos que o processo de compensação teorizado por Vigotski nos ajuda a avaliar os apoios e estratégias de mediações necessários para que, a partir destes, os sujeitos possam desenvolver processos compensatórios.

Vale lembrar que tanto a AAIDD quanto a CIF reconhecem que os apoios ou suportes podem consistir em: a) tecnologias simples ou de ponta que auxiliem em tarefas cotidianas ou em sistemas de comunicação; b) em recursos humanos, como uma pessoa do convívio familiar que possa orientar um sujeito em tarefas do dia a dia por este não ter autonomia para realizar sozinho, ou alguém especializado que trabalhe individualmente com uma pessoa em uma atividade determinada. Em outras palavras, propiciar instrumentos que deem suporte aos processos compensatórios é o primeiro passo para que este processo possa ser desencadeado.

A ideia de pensar em instrumentos que ampliam as condições de apropriação cultural que 
viabilizam as possibilidades de desenvolvimento da pessoa com deficiência relaciona-se ao próprio conceito de instrumento que aparece nos estudos da perspectiva histórico-cultural. Os instrumentos são elementos externos aos sujeitos. São construídos fora deles e têm a função de provocar mudanças nos objetos e controlar processos da natureza (VIGOTSKI, 2009). Especificamente neste caso, pensamos que estes podem se concretizar como artefatos ou suportes que contribuiriam para compensar as limitações dos sujeitos, e assim, colaborar para que o processo de compensação se constitua, favorecendo o desenvolvimento.

Neste contexto, recursos pedagógicos que atendam às necessidades educacionais dos alunos são fundamentais. Por exemplo, tanto recursos de tecnologias assistivas quanto da comunicação alternativa podem contribuir como instrumentos que favoreçam a interação e comunicação do aluno com deficiência múltipla não oralizado e, assim, possibilitem novas formas de reorganizar a linguagem que é fundamental para a sua aprendizagem escolar. Em outros termos, a partir da aprendizagem da comunicação alternativa, o aluno além de compensar a sua não oralidade, passa a ter suporte para se apropriar do sistema simbólico e, assim, estruturar a linguagem. Ainda sobre a comunicação alternativa, podemos dizer que ela pode ser vista como uma ferramenta, mas também como um instrumento psicológico a partir do momento em que o sujeito se apropria dela e a utiliza como mediadora entre si e o mundo ao seu redor. Claro que não temos a pretensão de esgotar o tema, mas compreendemos que as proposições de Vigotski precisam ser utilizadas como suporte das análises e reflexões sobre o processo de aprendizagem para avançarmos na produção do conhecimento $\mathrm{e}$ interpretarmos seus conceitos à luz do tempo presente, considerando os avanços científicos e tecnológicos e as condições sociais vigentes.

Recursos humanos também se constituem como importantes elementos desse processo. Nas postulações sobre a compensação, verificamos que o outro faz toda a diferença como recurso mediador. Nosso raciocínio valoriza as diversas possibilidades que indivíduos podem ter atuando na mediação dos processos de aprendizagem (VIGOTSKI, 1997; 2011). Nesse contexto, podemos levar em consideração que no processo de escolarização podem assumir o papel de mediadores o professor regente, o docente que atua no $\mathrm{AEE}$, a professores extraclasse, os próprios colegas de sala, dentre outros. Rocha (2018) destaca a importância da atuação do professor regente (seja do ensino comum ou da classe especial), do professor agente de apoio à inclusão e do docente do AEE. Em sua análise, ainda é necessário que se refine a atuação desses profissionais, privilegiando-se o trabalho colaborativo, como já sinalizado anteriormente.

Assim como nas proposições da AAIDD e da CIF, na análise das entrevistas, notamos que foi unânime a opinião de que para a efetivação da escolarização de sujeitos com deficiência múltipla, é fundamental que os apoios às necessidades educacionais não se restrinjam ao âmbito pedagógico ou ao espaço da escola. Nos alunos acompanhados por nossas investigações, além do serviço educacional, era difícil eles terem acesso a outros suportes da saúde, por exemplo, que seriam importantes para o seu desenvolvimento.

Os suportes da saúde e das demais áreas (serviço social, transportes e outros) favorecem as intervenções realizadas pela educação, a qual, por sua vez, possibilita processos de compensação conforme já discutimos. O trecho a seguir contribui para a nossa análise de como os apoios, para além do contexto educacional, precisam ser elaborados, desenvolvidos e/ou disseminados pelo poder público:

O registro comparável da incapacidade entre diferentes áreas políticas e o desenvolvimento de estatísticas e sistemas de indicadores compatíveis são importantes para sistemas equitativos de prestação de serviços e monitoramento. Por exemplo, é possível ver se indivíduos com níveis similares de dificuldade estão recebendo níveis similares de suporte ao longo do espectro de idade em situações onde há diferentes sistemas para o cuidado de idosos e jovens com incapacidades. A consistência também possibilita que uma população cliente seja comparada com a população geral e necessidades não atendidas sejam estimadas. (OMS, 2013, p. 84)

As propostas tanto da AAIDD quanto da CIF para a construção de planos de apoio contribuem não apenas para a qualidade de vida das pessoas com deficiências, mas também para pensarmos em suportes que possam ser utilizados para o caso da escolarização de sujeitos com deficiências severas. Dentre estes planos, destacamos o fornecimento de "modelos" (propostas) para integrar as informações baseadas em incapacidades e em currículos, além de informações educacionais e dados clínicos que podem ser úteis para a educação. Rocha (2018) apresenta uma proposta para a construção de apoios. Vejamos: 
FIGURA 1 - Processo para a construção de proposta de apoios

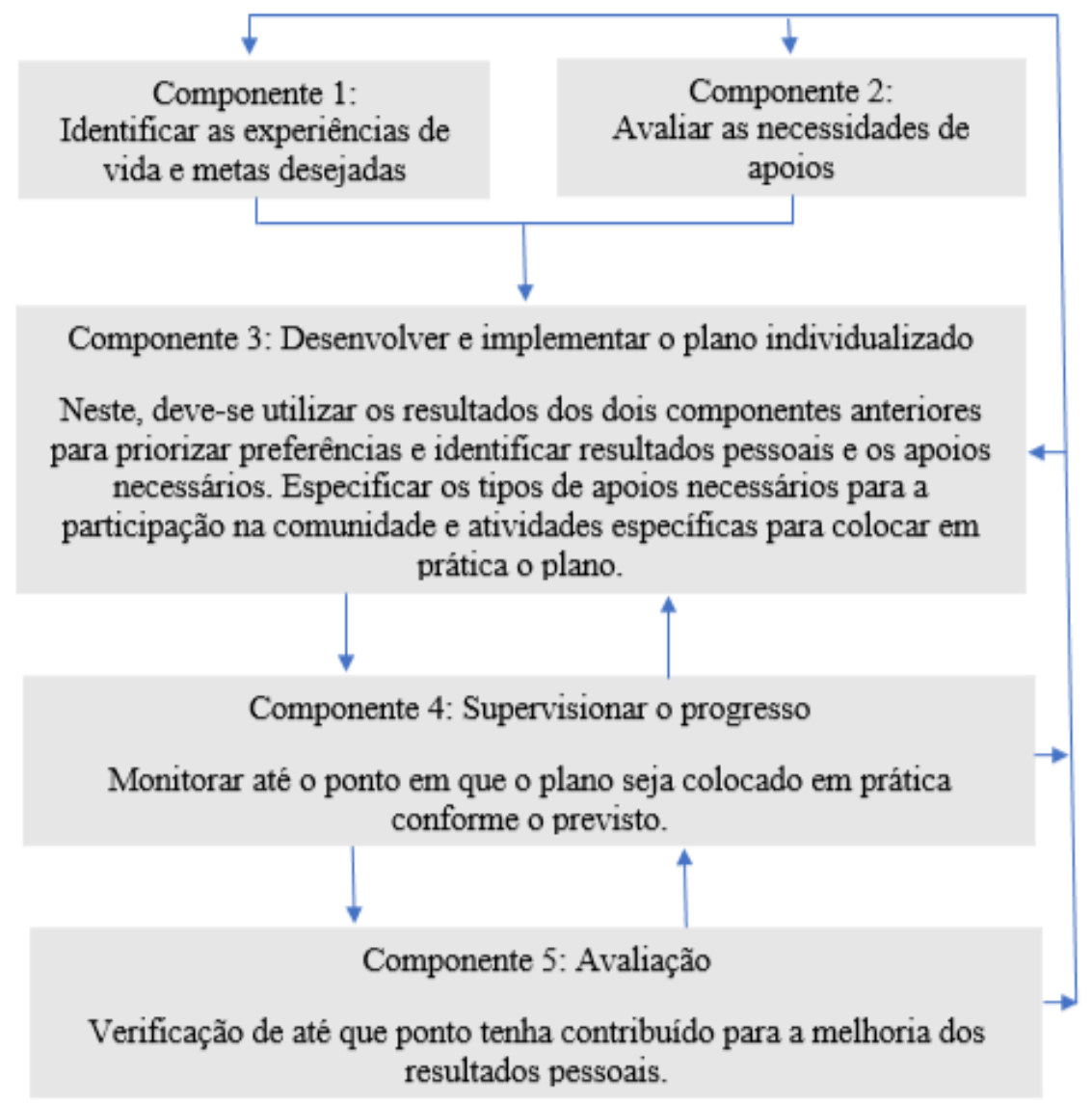

Fonte: Elaborado por Rocha (2018), com base na AAIDD (2011, p. 179)

Conforme podemos observar na figura 1 , as propostas da CIF e da AAID também indicam a necessidade de construção e utilização de planos educacionais individualizados. Verificamos que tais planos já estão presentes em muitas escolas. No entanto, ainda carecem de uma construção mais colaborativa e de uma aplicação mais efetiva, a fim de garantir condições institucionais efetivas para a plena inserção dos sujeitos com deficiência múltipla nas práticas educativas.

Em se tratando de sujeitos com múltiplas deficiências, devemos garantir suportes e apoios escolares pertinentes as especificidades de aprendizagem, criando aos mesmos possibilidades de apropriação dos conceitos escolares e do seu desenvolvimento cultural. Em outros termos, o processo de escolarização pode colaborar com a reorganização neurológica e a reestruturação das funções psicológicas dos limites impostos pelas condições orgânicas (impeditivos ao desenvolvimento), por meio das práticas sociais que envolvem a aprendizagem (SOUZA; PLETSCH,
2015). Para isso, a garantia de suportes e apoios pertinentes e adequados é indispensável para que possa ocorrer a compensação social da deficiência.

Para concluir, o que nossas pesquisas têm mostrado é que as pessoas com deficiência múltipla necessitam de suportes e apoios que tanto a escola comum quanto a escola especial não têm oferecido. Em grande medida, as práticas e intervenções têm focalizado as impossibilidades de aprendizagem ou, no máximo, atividades de socialização, as quais certamente são relevantes, mas não afetam os sujeitos de forma a garantir a apropriação da cultura.

Outro aspecto que não podemos omitir ao discutir as possibilidades de escolarização de pessoas com deficiência múltipla severa diz respeito às condições concretas de existência dessa população. Muitas vivem em condições sociais precárias, sem acesso aos serviços de saúde, assistência e programas de estimulação precoce, os quais ainda são urgentes para que os sujeitos possam construir caminhos internos que compensam sua deficiência e, assim, ampliarem as possibilidades de sua condição humana. 
Este artigo traz elementos que precisam ser aprofundados e problematizados em novas pesquisas, a partir de diferentes referenciais teóricos. Por outro lado, compreendemos que a partir das reflexões aqui apresentadas, não há como discutir caminhos possíveis para a escolarização sem garantir o oferecimento de apoios adequados às diferentes demandas que estes sujeitos apresentam.

\section{Notas}

1 Financiamento: FAPERJ e CNPq.

2 Disponível em: http://r1.ufrrj.br/im/oeeies/

3 Dados publicados no documento: A consolidação da inclusão escolar no Brasil 2003 a 2016 (BRASIL, 2016, p. 406).

4 Projeto de Pesquisa "A ESCOLARIZAÇÃO DE ALUNOS COM MÚLTIPLAS DEFICIÊNCIAS EM UMA ESCOLA PÚBLICA DA BAIXADA FLUMINENSE: formação de professores e processos de ensino e aprendizagem", financiado pela FAPERJ (Processo E-26/112.261/2012).

5 Pertencente ao campo das tecnologias assistivas, "[...] a comunicação alternativa envolve o uso de gestos manuais, expressões faciais e corporais, símbolos gráficos, fotografias, gravuras, desenhos, linguagem alfabética e ainda objetos reais, miniaturas, voz digitalizada, dentre outros, como meio de efetuar a comunicação face a face de indivíduos incapazes de usar a linguagem oral. Ela é considerada como uma área que se propõe a compensar temporária ou permanentemente a dificuldade do indivíduo em se comunicar" (GARCIA; PASSONI, 2008, p.11).

6 Projeto de Pesquisa Escolarização e desenvolvimento de alunos com deficiência intelectual e múltipla na Baixada Fluminense, financiado pelo Programa Jovem Cientista do Nosso Estado da FAPERJ (Processo $\mathrm{n}^{\circ}$. E26/201.535/2014) e pelo CNPq por meio do edital Ciências Humanas, Sociais e Sociais Aplicadas (Processo 442864/2015-9) e pela bolsa de produtividade do CNPq nível 2.

7 Agradecemos à bolsista de Iniciação Científica (PIBIC/CNPq/UFRRJ) Julinete Vieira da Fonseca Santos pela colaboração na sistematização dos dados de campo.

8 Termo utilizado por um dos municípios participantes para nomear o profissional mediador que atua acompanhando diretamente o aluno que tenha esse tipo de necessidade.

\section{Referências}

AAIDD. Discapacidad intelectual: defición, clasificácion ysistemas de apoyo. Asociación Americana de Discapacidades Intelectuales y del Desarrollo. 11. ${ }^{a}$ Edición. Traducción Miguel Ángel Verdugo Alonso. Edición: Alianza Editorial, S. A. Madrid, 2011.

ARAÓZ, S. M. M. de. Inclusão de alunos com deficiência múltipla: análise de um programa de apoio. 2010. 185 f. Tese (Doutorado em Educação Especial) - UFSCAR, SP, 2010.

ARAÓZ, S. M. M.; COSTA, M. da P. R. da. Deficiência múltipla: as técnicas Mapa e Caminho no apoio à inclusão. Jundiaí, Paco Editorial, 2015.

BERNARDO, A. I. J. A inclusão de um aluno com multideficiência na escola: estudo dos comportamentos de interacção entre pares. 2010. 111f. Dissertação apresentada à Escola Superior de Educação de Lisboa para obtenção de grau de mestre em Ciências da Educação - Especialidade Educação Especial. Lisboa, 2010.

BRASIL. Lei de Diretrizes e Bases da Educação Nacional (Lei no 9394/96). Brasília, 1996.

Programa de Capacitação de Recursos Humanos do Ensino Fundamental: Deficiência Múltipla. Brasília, DF: Ministério da Educação, Secretaria de Educação Especial. (Série Atualidades Pedagógicas). Brasília, 2000.

. Política Nacional de Educação Especial na Perspectiva da Educação Inclusiva. Brasília, 2008.

. Resolução no 4, de 02/10/09. Institui

Diretrizes Operacionais para o AEE na Ed. Básica, modalidade Educação Especial. Brasília, 2009. Decreto $\mathrm{n}^{\circ} 6.949$, de 25 de agosto de 2009.

. A consolidação da inclusão escolar no Brasil 2003 a 2016. Ministério da Educação/ Secretaria de Educação Continuada, Alfabetização, Diversidade e Inclusão Diretoria de Políticas de Educação Especial Esplanada dos Ministérios, Brasília, 2016.

DAINEZ, D. Constituição humana, deficiência e educação: problematizando o conceito de 
compensação na teoria histórico-cultural. 2014. 132f. Tese (doutorado) - Universidade Estadual de Campinas, Faculdade de Educação. Campinas, SP: 2014.

DAINEZ, D.; SMOLKA, A. L. B. O conceito de compensação no diálogo de Vigotski com Adler: desenvolvimento humano, educação e deficiência. In: Educação e Pesquisa. São Paulo, v. 40, n. 4, p. 1093-1108, out./dez. 2014.

FRIEDRICH, J. Lev Vigotski: mediação, aprendizagem e desenvolvimento - uma leitura filosófica e epistemológica. Inserir edição. Mercado das Letras, Campinas/SP, 2012.

GARCIA, J. C. D.; PASSONI, I. R. Tecnologia Assistiva nas Escolas. Inserir edição. São Paulo, SP: Instituto de Tecnologia Social, 2008.

GLAT, R.; BLANCO, L. de M. V. Educação Especial no contexto de uma Educação Inclusiva. In: GLAT, R. (org.). Educação Inclusiva: cultura e cotidiano escolar. (Coleção Questões atuais em Educação Especial, v. VI), Editora Sete Letras, p. 15-35, Rio de Janeiro, 2007.

KASSAR, M. C. M. Deficiência múltipla e educação no Brasil-discurso e silêncio na história dos sujeitos. Inserir edição. Campinas: Autores Associados, 1999.

LIMA, N. A. C.; ARAÚJO, A. C. B.; MORAES, B. Problemas fundamentais da defectologia: aproximações preliminares à luz do legado de Vigotsky. Revista Eletrônica Arma da Crítica. Ano 2: Número especial. Dez, 2010.

MAIA, S. R.; GIACOMINI, L.; ARAÓZ, S. M. M. de. Desenvolvimento da aprendizagem em crianças com Deficiência Múltipla Sensorial. In: COSTA, M. da P. R. da (Org.). Múltipla Deficiência: Pesquisa\& Intervenção. Pedro \& João Editores, São Carlos, SP, 2009.

MAIA, S. R.; GIACOMINI, L. Avaliação em pessoas com surdocegueira e deficiência múltipla sensorial. Centro de Recursos nas Áreas de Surdocegueira e Deficiência Múltipla Sensorial. AHIMSA - Associação Educacional pra Múltipla Deficiência. São Paulo, 2010. Disponível em: http://escritades.dominiotemporario.com/doc/01AE E_DMU_Aquis_Ling.pdf. Acesso em: janeiro de
2017.

MARIN, M.; BRAUN, P. Ensino colaborativo como prática de inclusão escolar. In: GLAT, Rosana; PLETSCH, Márcia Denise. Estratégias educacionais diferenciadas para alunos com necessidades especiais. Rio de Janeiro: EdUERJ, 2013. p. 49-64.

MOREIRA, F. D. dos S. Comunicação alternativa tátil para crianças com deficiência múltipla sensorial. Revista Benjamin Constant. Ano 23 n. 60 v. 1. ISSN on-line 1984-6061 jan.-jun, 2017. Disponível em: http://www.ibc.gov.br/?catid=14\&blogid=1\&itemid $=407$. Acesso em: julho de 2018 .

. The contribuition of tatile simbols for the commumication of children with multiple sensory disability. European Journal of Special Educacion Research. V. 3. Issue 4. ISSN 2501 -2428, 2018.

NUNES, C. Aprendizagem activa na criança com multideficiência: guia para educadores. Inserir edição. Ministério da Educação de Portugal, Lisboa, 2001.

NUNES, I. M. Política de educação especial para alunos com diagnóstico de deficiência múltipla: contornos e tensões. 240f. Tese (Doutorado em Educação), Universidade Federal do Espírito Santo, Vitória, 2016.

ORLANDO, R. M.; CAIADO, K. R. M. Professores universitários com deficiência: trajetória escolar e conquista profissional. Revista Educação e Realidade, v. 39, n. 3. P. 811-830, jul./set, 2014.

OMS. Classificação Internacional de Funcionalidade, Incapacidade e Saúde. Organização Mundial da Saúde (OMS). Direção Geral da Saúde. Tradução e Revisão: Amélia Leitão. Lisboa, 2004.

. Organização Mundial da Saúde Como usar a CIF: Um manual prático para o uso da Classificação Internacional de Funcionalidade, Incapacidade e Saúde (CIF). Versão preliminar para discussão. Outubro de 2013. Genebra: OMS, 2013.

PADILHA, A. M. L. Práticas educativas: perspectivas que se abrem para a Educação 
Especial. Educação \& Sociedade. Ano XXI, n 71, Julho, 2000. Disponível em: http://www.scielo.br/pdf/es/v21n71/a09v2171.pdf Acessado em maio de 2017.

PLETSCH, M. D. Deficiência múltipla: formação de professores e processos de ensino-aprendizagem. Cadernos de Pesquisa, v. 45, p. 12-29, 2015.

PLETSCH, M. D.; ROCHA, M. G. de S. da; OLIVEIRA, M. C. P. de. Organização e oferta do Atendimento Educacional Especializado para alunos com deficiência intelectual e múltipla na Baixada Fluminense. Revista Linhas - PPGE/UDESC, 2016.

PLETSCH, M. D.; PAIVA, C. Por que as escolas continuam "laudando" alunos com deficiência intelectual?. Artigo aprovado para publicação na Revista de Educação Especial da Universidade Federal de Santa Maria. V. 31. Santa Maria, RS, 2018.

ROCHA, M. G. de S. da. Processos de ensino e aprendizagem de alunos com múltiplas deficiências no AEE à luz da teoria histórico-cultural. 2014. 233 p. Dissertação (Mestrado em Educação) Instituto de Educação / Instituto Multidisciplinar / PPGEduc / UFRRJ, Nova Iguaçu, RJ. 2014.

ROCHA, M. G. de S. da.; PAIVA, C. De. O desenvolvimento das estruturas psicológicas superiores em alunos com deficiência múltiplas: uma análise a partir do uso de recursos de tecnologia assistiva. In: PLETSCH, M. D \& SOUZA, F. F. de. (Orgs.) Observatório de Educação Especial e Inclusão Escolar: balanço das pesquisas e das práticas na Baixada Fluminense. São Carlos: Marquezine \& Manzini: ABPEE, 2015.

ROCHA, M. G. de S. da; PLETSCH, M. D. Deficiência múltipla: disputas conceituais e políticas educacionais no Brasil. Revista Cadernos de Pesquisa. v. 22, n. 1, São Luís, MA, jan./abr. 2015.

ROCHA, M. G. de S. da; PLETSCH, M. D. O atendimento educacional especializado para alunos com múltiplas deficiências: políticas públicas e desafios para a escolarização In: Anais do VII Congresso Brasileiro de Educação Especial. Universidade Federal de São Carlos: São Carlos, SP, 2016.

ROCHA, M. G. de S. da; PLETSCH, M. D.
Comunicação alternativa como instrumento externo de compensação: possibilidades para a aprendizagem de alunos com múltiplas deficiências. In: Dossiê Questões contemporâneas sobre a Educação Especial na Perspectiva da Educação Inclusiva. Revista Interinstitucional Artes de Educar. v. 4, n. 1. p. ?-?. Rio de Janeiro, março de 2018. Disponível em http://www.epublicacoes.uerj.br/index.php/riae. Acessado em junho/2018.

ROCHA, M. G. de S. da. Os sentidos e significados da escolarização de sujeitos com deficiência múltipla. 2018. 291p. Tese (Doutorado em Educação) Instituto de Educação/Instituto Multidisciplinar/PPGEduc/UFRRJ, Nova Iguaçu, RJ. 2018.

SOUZA, M. M. Surdocegueira e deficiência múltipla sensorial: análise do Programa Atendimento Domiciliar \& Famílias Apoiadas. Dissertação (Mestrado). 2010. 183 f. Faculdade de Educação, Universidade de São Paulo, São Paulo, 2010.

SOUZA, F. F. Políticas de educação inclusiva: reflexões sobre os impactos no desenvolvimento de um aluno com deficiência múltipla. In: SMOLKA, A. L. B.; NOGUEIRA, A. L. H. (Org.). Estudos na perspectiva de Vygotski: gênese e emergência das funções psicológicas. Mercado das Letras.

Campinas, SP, 2013. p. 151-172.

SOUZA, F. F.; PLETSCH, M. D. Atendimento educacional especializado: das diretrizes políticas à escolarização dos alunos com deficiência intelectual. Educação e Fronteiras. On-Line, Dourados/MS, v.5, n.13, p.137-148, maio/ago. 2015.

SOUZA, F. F. de; DAINEZ, D. Condições e modos de participação de um aluno com deficiência múltipla no cotidiano escolar do ensino fundamental. Cadernos de Pesquisa. v. 23, n. 2, mai./ago. São Luís. MA, 2016. Disponível em: http://www.periodicoseletronicos.ufma.br/index.php /cadernosdepesquisa/article/view/4616 Acessado em: abril de 2017.

TEIXEIRA, E.; NAGLIATE, P. de C.; REIS, T. Análise das publicações sobre múltipla deficiência na Europa. In: COSTA, M. da P. R. da (Org.). Múltipla Deficiência: Pesquisa\& Intervenção. Pedro 
\& João Editores, São Carlos, SP, 2009.p.?-?.

VAN DER VEER, R.; VALSINER, J. Vygotsky uma síntese. Inserir edição. Ed. Loyola, SP, 2009. VIGOTSKI, L. S. Fundamentos da defectologia .Obras escogidas- volume V. Visor. Madrid, 1997. A construção do pensamento e da linguagem. Textos de Psicologia (Texto integral, traduzido do russo Pensamento e Linguagem) 496 p. São Paulo: WMF Martins Fontes, 2009.

. A defectologia e o estudo do desenvolvimento e da educação da criança anormal. Educação e Pesquisa. v. 37, n.4, p. 861-870, dez., 2011.

\section{Sobre as autoras}

Maira Gomes de Souza da Rocha é Mestre e Doutora em Educação pelo Programa de Pós-Graduação em Educação, Contextos Contemporâneos e Demandas Populares (PPGEduc) da Universidade Federal Rural do Rio de Janeiro (UFRRJ). Orientadora Educacional e Professora do Atendimento Educacional Especializando (AEE) da Rede Municipal de Educação de Duque de Caxias.

Márcia Denise Pletsch é Professora Associada do Departamento Educação e Sociedade e do Programa de PósGraduação em Educação, Contextos Contemporâneos e Demandas Populares (PPGEduc) da Universidade Federal Rural do Rio de Janeiro (UFRRJ). Jovem Cientista do Estado do Rio de Janeiro da FAPERJ e pesquisadora do CNPq.

Recebido em julho de 2018.

Aprovado em outubro de 2018. 